\title{
Evaluating the effects of floral resource specialisation and of nitrogen regulation on the vulnerability of social bees in agricultural landscapes
}

\author{
Wiebke KÄMPER ${ }^{1}$, Christiane WeINER ${ }^{2}$, Sara KÜHSEL ${ }^{2}$, ${\text { Christian } \text { STORM }^{3} \text {, Thomas EltZ }}^{1}$, \\ Nico BLÜTHGEN ${ }^{2}$ \\ ${ }^{1}$ Department of Animal Ecology, Evolution and Biodiversity, Ruhr-University Bochum, Universitätsstraße 150, 44780, \\ Bochum, Germany \\ ${ }^{2}$ Department of Biology, Ecological Networks, Technische Universität Darmstadt, Schnittspahnstraße 3, 64287, \\ Darmstadt, Germany \\ ${ }^{3}$ Department of Biology, Chemical Plant Ecology, Technische Universität Darmstadt, Schnittspahnstraße 4, 64287, \\ Darmstadt, Germany
}

Received 16 July 2016 - Revised 3 October 2016 - Accepted 13 October 2016

\begin{abstract}
The abundance and the diversity of bumblebees have been declining for the past decades. While some species remain abundant and widespread, others have experienced vast declines. We tested if diet breadth and exclusiveness of floral resource use affected abundance and land-use response of bumblebees and honeybees in heterogeneous agricultural landscapes. Based on an ecological niche modelling approach, we discovered that three of 13 species (12 Bombus spp. and A. mellifera) responded negatively to land use, while no species responded positively. Overall abundance as well as land-use response of different bee species was unrelated to resource use. The generalist forager $B$. lapidarius, the slightly more specialised forager B. terrestris/lucorum species complex and the specialist forager $B$. wurflenii declined most with land use. Moreover, we found that honeybees and two bumblebee species contained higher levels of nitrogen than other non-predatory Hymenoptera and performed almost perfect homeostasis despite variable nitrogen contents of floral resources. We conclude that at least common species of social bees have good nitrogen homeostasis capacity. Generally, our data do not support the notion that species with more specialised floral resource use are more likely to suffer from land use.
\end{abstract}

resource specialisation / pollinator / land-use response / homeostasis / biodiversity

\section{INTRODUCTION}

In temperate regions of the Northern hemisphere, honeybees and bumblebees are the most economically important pollinators of crops

Electronic supplementary material The online version of this article (doi:10.1007/s13592-016-0480-4) contains supplementary material, which is available to authorized users.

Corresponding author: W. KÄMPER, Wiebkekaemper@gmail.com

Manuscript editor: Alexandra Klein and wildflowers (Goulson 2003; Gallai et al. 2009). Thus, understanding declines in abundance, distribution and diversity of those pollinator species has been the subject of many ecological studies (e.g. Carvell 2002; Biesmeijer et al. 2006; Cameron et al. 2011; Goulson et al. 2015). However, especially in bumblebees, it is still unclear why some species decline strongly or have even gone extinct while others remain relatively stable in Europe, North America and Asia (Williams and Osborne 2009; Goulson et al. 2015). 
Species differences in plant choice have been suggested as a key factor explaining the population trends of wild bees with particularly those bees declining whose preferred forage plants have been in decline (Scheper et al. 2014; Weiner et al. 2014). Additionally, in bumblebees, diet breadth was found to be positively related to local abundance (Goulson et al. 2008). However, bumblebee species with large diet breadths likely exhibit an overlap in floral diets with other bee species (Goulson and Darvill 2004; Thomson 2006; Goulson and Sparrow 2009). With many bee species using the same floral resources, maximising diet breadth is one way to maintain a stable food supply. In contrast, enhancing diet exclusiveness by specialising on a limited number of plant species, which are not frequently visited by other species, can also lead to a stable food supply (Heinrich 1976; Ishii et al. 2008). If the floral resource spectra are a consequence of floral resource partitioning, we expect species that do not overlap largely with other species to be more abundant compared with species with overlapping diets if their preferred floral resources are available. However, honeybees and bumblebees are social insects that have long flight seasons and high pollen requirements for raising offspring. Consequently, true specialisation is highly unlikely, as plants from a restricted plant taxon will likely not provide resources throughout the entire flight season for allowing a social lifestyle.

The composition and diversity of floral resources available to bees is altered by land use (Biesmeijer et al. 2006; Clough et al. 2014). With species differing in plant choice, their response to land use might differ, but studies on whether plant choice predicts land-use responses of different bee species are scarce. However, some studies found an association between the occurrence of a bee species and their preferred host plants and suggested that often the decline of host plants was related to land use (Kleijn and Raemakers 2008; Scheper et al. 2014; Weiner et al. 2014).

Furthermore, land use can change the quality of floral resources (Atasay et al. 2013). Nitrogen is readily added in the form of fertilisers and faeces of grazing animals, and Atasay et al. (2013) showed that the nitrogen content of pollen increased with nitrogen fertilisation. A high protein content of dietary pollen increased the performance of individual workers and entire colonies in both honeybees and bumblebees (Regali and Rasmont 1995; Tasei and Aupinel 2008; Di Pasquale et al. 2013). It is unclear to what extent the nitrogen content of bees is a reflection of the nitrogen content of forage plants on a landscape scale or more to the point in the present context, to what extent bees can and will regulate the changes in nitrogen content of their diet.

In this study, we investigated how floral resource diversity (diet breadth) and complementary floral resource specialisation (diet exclusiveness) are related to three community-level variables of bumblebees and honeybees:

1. Their average local abundance (per plot)

2. Their plot occupancy, i.e. the number of plots at which a species was found

3. Their average response to land-use intensity, i.e. the land-use intensity under which a given species has been observed

Moreover, we investigated if the response of flowering plants to different land-use intensities explained the response of bee species to different land-use intensities. And finally, in a specificspecies approach, we investigated the effect of land use and nitrogen in floral resources on body nitrogen content in Apis mellifera and two Bombus spp.

\section{MATERIALS AND METHODS}

\subsection{Study sites and data collection}

All grassland plots are part of the Biodiversity Exploratory 'Schwäbische Alb', a UNESCO biosphere reserve in southwestern Germany (www.biodiversity-exploratories.de). We analysed data from four different field surveys (Table I). All field surveys were conducted at a subset of the same 50 grassland plots, except the survey in 2007 on additional 30 sites. The 50 experimental grassland plots are on average $6.22 \pm 5$ ha large and $8.22 \pm 4.82 \mathrm{~km}$ apart. The grasslands represent most of the variation in land use typical for grasslands in Germany, from rarely managed grasslands (including slopes with shallow soils usually used as sheep pastures) to highly 
Table I. Overview of field surveys.

\begin{tabular}{lllll}
\hline Field surveys & $\begin{array}{l}\text { Weiner et al. } \\
(2011)\end{array}$ & $\begin{array}{l}\text { Weiner et al. } \\
(2014)\end{array}$ & $\begin{array}{l}\text { Kühsel and Blüthgen } \\
(2015)\end{array}$ & $\begin{array}{l}\text { Kämper } \\
\text { (unpublished) }\end{array}$ \\
\hline Year & 2007 & 2008 & 2012 & 2012 \\
Number of plots & 30 & 39 & 15 & 46 \\
Number of visits & 1 & $1.95(1-4)$ & $4.2(2-10)$ & $2.69(1-3)$ \\
Dates & May 31-Aug 25 & May 24-Aug 22 & May 23-Aug 25 & Jun 6-Jul 10 \\
Time spent per visit & 6 h & 6 h & 6 h & 80 min \\
Land - use information & No & Yes & Yes & Yes \\
\hline
\end{tabular}

fertilised and intensively used meadows and pastures. For details on study regions and site selection, see Fischer et al. (2010).

In all field surveys, the order of plot visitation occurred randomly to avoid any confounding effects of e.g. land use. During each visit to each plot (for details on e.g. duration, see Table I), we walked multiple rounds along a 200-m long and ca. 6-m wide transect $\left(1200 \mathrm{~m}^{2}\right)$ consisting of four perpendicular 50-m sections at a constant pace and recorded all interactions of honeybees and bumblebees with flowering plants (see Table I). We cannot exclude occasionally having recorded the same bee individual more than once. In all field surveys, observations started at 8:00 the earliest, and were completed by $18: 30$ the latest.

In the following text, average local abundance of a species refers to the average number of individuals recorded per hour and per plot at which it occurred (see statistical analysis) and is a measure of whether a species is common or rare in a particular plot, while plot occupancy refers to the number of plots the species was recorded on and allows statements about how common or rare a species is in the region. To assess plant abundances on each plot, we counted open flower heads of bee-visited plant species on the 1200$\mathrm{m}^{2}$ transect or, in highly abundant species, estimated it by extrapolation from a small area.

For the analysis of nitrogen content, we collected additional samples from all 50 grassland plots between June 24 and July 192013 (see below).

\subsection{Nitrogen content and homeostasis}

We caught 91 A. mellifera, 58 Bombus hortorum and 131 Bombus lapidarius with sweep nets and collected samples of four plant species (Rhinanthus alectorolophus, Prunella vulgaris, Trifolium pratense and Trifolium repens), which are known from former studies to be frequently visited by honeybees and bumblebees for nectar and pollen, on each plot.

Individual bees were stored in glass vials and killed in a freezer at $-18^{\circ} \mathrm{C}$. Then, the bees were pinned, identified to species level and dried at $70{ }^{\circ} \mathrm{C}$ for 3 days. For the nitrogen analysis, we removed the abdomen, wings, legs and antennae, and for each plot, pooled 1-4 individuals per species $($ mean $=2.8)$. We ground the pooled samples and weighed them in a tin cup with an analytical balance (average tissue analysed $5.06 \mathrm{mg} \pm 0.29$ (mean $\pm \mathrm{sd}$ ); Sartorius, Germany, readability $0.01 \mathrm{mg}$ ).

On each plot, whenever available, we collected the corolla (including stamen and pistil) of 30 $R$. alectorolophus (at 12 plots) and $P$. vulgaris (28) and inflorescences of $20 \mathrm{~T}$. pratense (49) and T. repens (28), respectively, and stored them in separate paper bags per plot and species. Samples were dried, ground and weighed similarly to the animal samples $(5.01 \mathrm{mg} \pm 0.23($ mean $\pm \mathrm{sd}))$. We analysed complete inflorescences/corollae because collecting pure pollen is extremely timeconsuming and not feasible on such a large number of samples, especially in legumes, which include important forage species for bumblebees (Carvell 2002; Goulson and Darvill 2004). 
Analysing corbicula pollen (from bees) is likewise problematic because the pollen is mixed with an unknown amount of regurgitated nectar for transport on the bee's legs, biasing measurements of nitrogen content (Roulston et al. 2000; Leonhardt et al. 2007).

The nitrogen content $(\mathrm{N} \%)$ of the dry mass of animals and plants was determined by elemental analysis (gas-chromatography, Model EA 1108, Carlo-Erba, Italy). The accuracy was ascertained by certified material (Hay powder BCR 129 by LGC Standards, $94 \% \pm 5$ (mean $\pm \mathrm{sd}$ ), $n=38$, and Acetanilide by Hekatech, $101 \% \pm 4, n=76$ ). All analyses were carried out twice and mean values were used. Precision was determined by mean absolute deviation from the mean of both values (bees $N=2.1 \% \pm 1.7, n=258$; plants $N=3.3 \% \pm 2.7, n=342$ ).

\subsection{Statistical analyses}

For each bee species and field survey, we calculated the specialisation index $d$ ' (Blüthgen et al. 2006) and used the average $d$ ' per species in the subsequent analyses. Here, $d$ ' quantifies the exclusiveness of the resources used by a species compared to other bee species in the interaction network. We furthermore calculated the effective resource diversity $e^{H^{\prime}}$ based on Shannon entropy $H^{\prime}$ (Jost 2006). $e^{H^{\prime}}$ gives the diet breadth, i.e. the number of resource species if each resource was equally common. $d$ ' ranges from 0 (complete generalisation) to 1 (complete specialisation) and is not biased by total observation frequencies, whereas $e^{H^{\prime}}$ may systematically increase with sample size (Blüthgen et al. 2006). To control for this, we calculated a residual resource diversity $\Delta e^{H^{\prime}}$ after a regression between raw $e^{H^{\prime}}$ versus total number of individuals recorded, and used $\Delta e^{H^{\prime}}$ in the following analyses.

Before analyses, we corrected the local abundance for differences in sampling effort. Therefore, we calculated the average visits observed in $1 \mathrm{~h}$ for each plot and each field survey. We then calculated the average across the field surveys and used this average in the subsequent analyses. We log-transformed average local abundance for each species with the natural logarithm and tested all variables for their normality (Lilliefors-Test) and collinearity (Spearman's rank test). We then tested whether $d^{\prime}$ and $\Delta e^{H^{\prime}}$ were predictors for species average local abundance and plot occupancy with linear regressions.

To evaluate the ecological niche for each bee species with regard to land use, we calculated the abundance-weighted means (AWM) of land-use intensity (L) for each species based on one data set from 2008 and two from 2012. We again used the average local abundance corrected for sampling effort. The AWM(L) of a species $i$ is the sum product of proportion $p$ of individuals of species $i$ found on plot $s$ in relation to its total abundance, and the average land use $L$ of plot $s$ (Chisté et al. 2016).

$\mathrm{AWM}_{i}=\sum_{s=1}^{50} p_{s, i} L_{s}$

Thus, the AWM $(\mathrm{L})$ reflects the mean land-use intensity under which a given bee species has been observed. Statistically, we tested if the $\mathrm{AWM}(\mathrm{L}) \mathrm{s}$ of species deviated from their expected null distributions generated using a randomisation approach. The null model assumed that each bee species occurred on every plot with the same likelihood, and the number of plots at which a species was observed determined how often the null model chose the LUI (or mowing or fertilisation or grazing intensity) of random plots for each species. It calculated the AWM(L) values for 10,000 iterations, and as in any randomisation model, the proportion of the AWM(L)s from 10,000 iterations with greater or smaller AWM(L) respectively than the observed value provided the $p$ value of significance for the deviation between observed and expected values.

As a measure for land-use intensity, we used the average land-use intensity (LUI) index for each plot over 7 years (2006-2012). The LUI summarises the standardised intensity of the three main components of land use, namely mowing (cuts per year), annual fertilisation (kg nitrogen per hectare) and livestock grazing intensity (livestock units per hectare times number of days) (Blüthgen et al. 2012). The LUI index ranges from ca. 0.5 (low input or 
disturbance) to 3.5 (intensive land use). Additionally, to have a more detailed view on the effects of mowing, fertilisation and grazing intensity, we calculated AWM(L)s for each of the three components, respectively. Furthermore, we calculated the abundance-weighted standard deviation (AWSD) weighted by the proportion of abundance. AWSD reflects the niche breadth of each species. Because the land-use response of a bee species may be determined by how their associated plant species respond, the same method was applied to quantify the ecological niche of each visited plant species $j$ with regard to land use (replace $i$ by $j$ above). We calculated the abundance-weighted mean land-use response (AWM(L)) of all the food plants frequented by pollinator species $i\left(E_{i}\right)$, weighted by the number of interactions $a_{i j}$ between $i$ and $j$.

For the nitrogen analysis, we calculated the unweighted average $\mathrm{N} \%$ of plants for each plot and then tested if the average $\mathrm{N} \%$ of plants increased with land-use intensity. Furthermore, we tested if $\mathrm{N} \%$ of animals increased with LUI and $\mathrm{N} \%$ of plants. Therefore, we used the average land-use intensity (LUI) index of 2012 and 2013 and performed Pearson's correlations. Next, we calculated the homeostasis coefficient $H=1 / \beta$ for each bee species (see Sterner and Elser 2002), where $\beta$ is the slope of the linear regression of the $\log \mathrm{N} \%$ of the bee over the mean $\log \mathrm{N} \%$ of the four plant species at the same plots. Log $\mathrm{N} \%$ was calculated with the natural logarithm. $H$ ranges from 1 (conformer) to infinity (regulator). We regard negative slopes as an indication of no regulation (in accordance with Sterner and Elser (2002)), hence $H=\infty$, if $\beta<0$.

All statistical analyses were done with $\mathrm{R}$ version 3.1.1 for Macintosh OS X.

\section{RESULTS}

We recorded 12 bumblebee species (including the combined category Bombus terrestris/lucorum species complex; $n=5018$ observations) on 83 plant species. Honeybees $(n=1947)$ were observed on 59 plant species. We built interaction networks to illustrate the observed pollinatorplant interactions (Online supplement 1, Figure $1 \mathrm{~S}$ and Table S.1).

\subsection{Floral resource use}

Specialisation (exclusiveness) of bee species with regard to flower visitation was low (Table II; $d^{\prime}=0.25 \pm 0.1$ (mean \pm sd)), and, correspondingly, effective diversity of flowers visited high $\left(e^{H^{\prime}}=9.47 \pm 4.6\right)$. The degree of visitation specialisation $\left(d^{\prime}\right)$ neither predicted average local abundance nor plot occupancy, a measure for regional abundance (Table II; $F=0.002, P=0.96$ and $F=0.05, P=0.82$, both $n=13 \mathrm{spp}$.). Moreover, residual resource diversity of flowers visited $\left(\Delta e^{H^{\prime}}\right)$ did not predict plot occupancy $(F=0.34, P=0.57$, $n=13 \mathrm{spp}$.). Note, however, that no specialised bumblebee species $\left(d^{\prime}>0.35\right)$ could be found on more than 30 plots (Table II). Both specialised bumblebee species, Bombus soroeensis and Bombus wurflenii, showed a relatively exclusive use of certain plant species: Centaurea jacea and Campanula rotundifolia accounted for 24 and $19 \%$ of B. soroeensis visits ( $n=136)$, respectively, and Prunella grandiflora accounted for $57 \%$ of $B$. wurflenii visits ( $n=276$ ); only $B$. lapidarius also visited these three plant species.

Three of $13(23 \%)$ bee species occurred at significantly higher abundances on plots with low land-use intensity (LUI), i.e. the observed abundance-weighted mean of LUI was significantly lower than the expected abundanceweighted mean of LUI generated by the randomisation approach in $B$. lapidarius, the $B$. terrestris/lucorum species complex and B. wurflenii . No bee species responded significantly positive to land use (Table III). Looking at the three components of land use (Table IV), we found that four species were significantly more abundant on plots with low fertilisation intensity, five with low mowing intensity and one with low grazing intensity. In contrast, only two species were significantly more abundant on plots with high fertilisation intensity, none with high mowing intensity and two with high grazing intensity. 


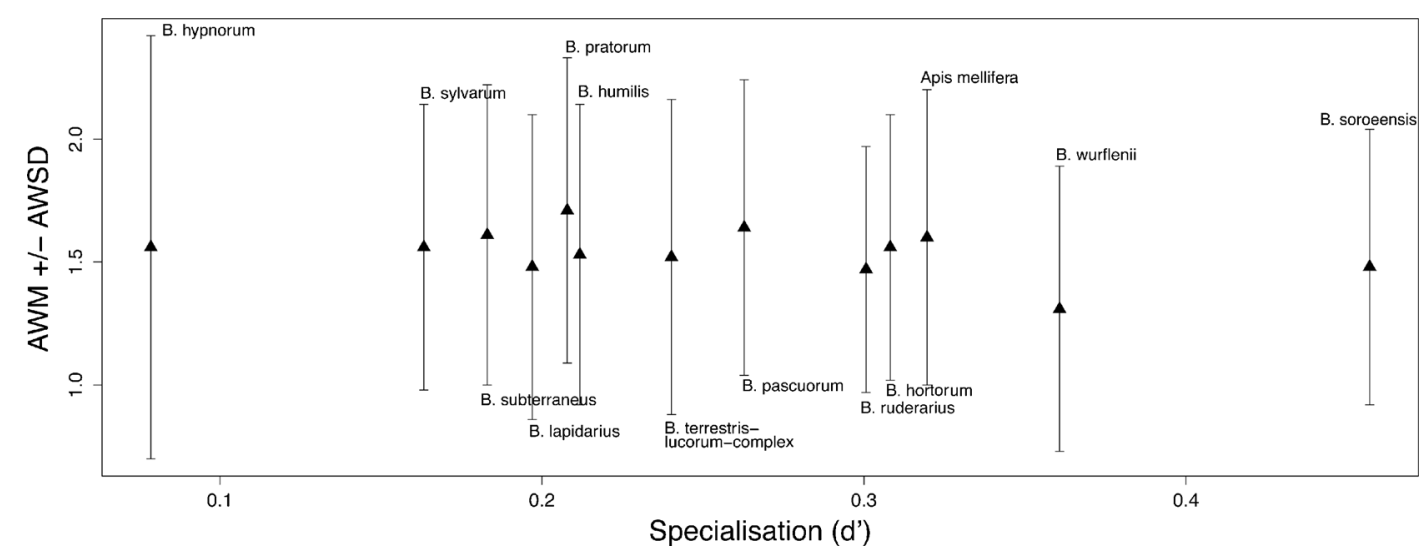

Figure 1. The specialisation of a species ( $d$ ') did not predict its land-use response, as indicated by the abundanceweighted mean $\operatorname{AWM}(\mathrm{L})$ of each bee species, which reflects the mean land-use intensity under which a given bee species has been observed. The AWSD is the abundance-weighted standard deviation which reflects the niche breadth of each species.

Neither the residual resource diversity of flowers visited $\left(\Delta e^{H^{\prime}}\right)$ nor the degree of specialisation $\left(d^{\prime}\right)$ of flowers visited predicted the land-use response of a species $(F=0.16, P=0.70, n=13$ spp.; Fig. 1: $F=2.39, P=0.15, n=13$ spp.). Thirty-six percent (61 of 168) of plant species visited by honeybees and bumblebees responded negatively to the LUI while only $7 \%$ responded positively to the LUI $(P<0.05$; online supplement 2, Table S.2). Alarmingly, in our study, especially plant species that are known to attract bees responded negatively to land use (e.g. C. rotundifolia $(P=0.001)$,

Table II. Average interaction specialisation at species level ( $\left.d^{\prime}\right)$, average effective diversity of interacting partners, average local abundance across all sites at which a species occurred, number of plant species visited and plot occupancy of bee species.

\begin{tabular}{llllll}
\hline Species & $d^{\prime}$ & $\begin{array}{l}\text { Effective } \\
\text { diversity }\end{array}$ & $\begin{array}{l}\text { Average } \\
\text { abundance }\end{array}$ & $\begin{array}{l}\text { Number of } \\
\text { plant species }\end{array}$ & $\begin{array}{l}\text { Number of } \\
\text { locations }\end{array}$ \\
\hline A. mellifera & 0.32 & 17.22 & 84.7 & 60 & 69 \\
B. hortorum & 0.31 & 8.02 & 20.5 & 20 & 43 \\
B. humilis & 0.21 & 9.54 & 17.6 & 34 & 51 \\
B. hypnorum & 0.08 & 3.36 & 0.2 & 4 & 6 \\
B. lapidarius & 0.20 & 17.00 & 89.6 & 69 & 70 \\
B. pascuorum & 0.26 & 7.69 & 42.8 & 47 & 71 \\
B. pratorum & 0.21 & 9.37 & 4.8 & 20 & 28 \\
B. ruderarius & 0.30 & 6.31 & 1.3 & 6 & 10 \\
B. soroeensis & 0.46 & 12.31 & 5.1 & 24 & 30 \\
B. subterraneus & 0.18 & 2.83 & 2.0 & 5 & 52 \\
B. sylvarum & 0.16 & 12.65 & 25.0 & 42 & 52 \\
B. terlluc-complex & 0.24 & 11.22 & 26.0 & 37 & 20 \\
B. wurflenii & 0.36 & 5.61 & 8.8 & 22 & \\
\hline
\end{tabular}


Table III. Results of the null model, which compares observed average weighted means $(A W M)$ with expected weighted means of LUI, by means of the number of plots honeybees or the bumblebee species occurred. The average weighted standard deviation (AWSD) reflects the niche breadth of each species. The asterisks indicate the significance levels between the observed and expected weighted means. Significant positive interactions are additionally marked in bold. Average land-use intensity values of 7 years (2006-2012) were used. $E_{i}$ shows the weighted mean land-use response of all the food plants frequented by pollinator species $i$.

\begin{tabular}{llllll}
\hline & & LUI & & & $E_{i}$ \\
\cline { 3 - 5 } Species & $\begin{array}{l}\text { Number } \\
\text { of locations }\end{array}$ & AWM \pm AWSD & AWMexp & $p$ & of plants visited \\
\hline A. mellifera & 42 & $1.6 \pm 0.60$ & 1.601 & 0.49 & 1.16 \\
B. hortorum & 32 & $1.56 \pm 0.54$ & 1.600 & 0.26 & 1.59 \\
B. humilis & 36 & $1.53 \pm 0.61$ & 1.601 & 0.08 & 1.08 \\
B. hypnorum & 3 & $1.56 \pm 0.86$ & 1.596 & 0.45 & 1.10 \\
B. lapidarius & 46 & $1.48 \pm 0.62$ & 1.601 & $<0.001 * * *$ & 1.08 \\
B. pascuorum & 44 & $1.64 \pm 0.60$ & 1.600 & 0.12 & 1.27 \\
B. pratorum & 21 & $1.71 \pm 0.62$ & 1.599 & 0.14 & 1.10 \\
B. ruderarius & 10 & $1.47 \pm 0.50$ & 1.601 & 0.23 & 1.32 \\
B. soroeensis & 21 & $1.48 \pm 0.56$ & 1.600 & 0.12 & 1.33 \\
B. subterraneus & 11 & $1.61 \pm 0.61$ & 1.601 & 0.49 & 1.90 \\
B. sylvarum & 40 & $1.56 \pm 0.58$ & 1.600 & 0.18 & 1.12 \\
B. ter/luc-complex & 36 & $1.52 \pm 0.64$ & 1.601 & $0.05 *$ & 1.35 \\
B. wurflenii & 18 & $1.31 \pm 0.58$ & 1.602 & $<0.001^{* * *}$ & 1.01 \\
\hline
\end{tabular}

Lotus corniculatus $(P<0.001)$, $P$. grandiflora $(P<0.001)$, $P$. vulgaris $(P<0.001)$, T. pratense $(P<0.001))$.

To assess which bee species are associated most with plant species that responded negatively to LUI, we calculated the weighted mean land-use response of all the food plants frequented by each pollinator species $\left(E_{i}\right)$. An average $E_{i}$ of 1.26 (range 1.00-1.90) showed that honeybees and bumblebees in the study area generally preferred to forage on plant species that decline with land use (Table III). Bombus wurflenii, B. lapidarius and Bombus humilis showed the lowest $E_{i}$ values. $E_{i}$ per bee species was not affected by its observed abundance-weighted mean of LUI ( $F=0.74, P=0.41, n=13$ spp. $)$.

\subsection{Nitrogen content and homeostasis}

The nitrogen content of inflorescences differed between plant species; $P$. vulgaris had the lowest nitrogen content $(1.44 \% \mathrm{~N} \pm 0.16$ (mean $\pm \mathrm{sd}$ )), followed by $R$. alectorolophus $(2.18 \% \mathrm{~N} \pm 0.26)$, whereas the two legumes $T$. pratense (3.27\% $\mathrm{N} \pm 0.23$ ) and $T$. repens (3.31\% $\mathrm{N} \pm 0.24)$ had the highest nitrogen contents. The average nitrogen content per plot was $2.89 \% \mathrm{~N} \pm 0.38$. As expected, average $\mathrm{N} \%$ of inflorescences increased with LUI $(r=0.36$, $P=0.011)$, as did $\mathrm{N} \%$ of $T$. pratense and $T$. repens, respectively $(r=0.50, P<0.001$; $r=0.39, P=0.006)$. Nitrogen content of $R$. alectorolophus and $P$. vulgaris did not increase significantly with LUI, respectively $(r=0.32$, $P=0.31 ; r=0.18, P=0.36)$.

A. mellifera $(12.08 \% \mathrm{~N} \pm 0.51 ; n=33)$ and B. lapidarius ( $12.08 \% \mathrm{~N} \pm 0.50, n=42)$ had an identical and similarly variable nitrogen content while $\mathrm{N} \%$ of $B$. hortorum (12.21\% $\mathrm{N} \pm 0.35$; $n=20$ ) was slightly higher and less variable. Bees were more constant in their nitrogen content $(\mathrm{CV}$ 0.037, range 0.029-0.042) than flowers (CV 0.092, range $0.07-0.119)$, suggesting a higher regulation. None of the species (A. mellifera, B. hortorum and $B$. lapidarius ) showed a consistent change of $\mathrm{N} \%$ with LUI $(r=-0.05, P=0.78 ; r=0.40$, 





Table V. Results of the Pearson's correlation between nitrogen content (\%) in plant species and three different bee species. $n$ gives the sample size.

\begin{tabular}{|c|c|c|c|c|c|c|c|c|c|}
\hline \multirow[t]{2}{*}{ Species } & \multicolumn{3}{|c|}{ A. mellifera } & \multicolumn{3}{|c|}{ B. hortorum } & \multicolumn{3}{|c|}{ B. lapidarius } \\
\hline & $r$ & $p$ & $n$ & $r$ & $p$ & $n$ & $r$ & $p$ & $n$ \\
\hline Plant average & 0.11 & 0.55 & 35 & -0.32 & 0.16 & 21 & -0.08 & 0.62 & 43 \\
\hline R. alectorolophus & 0.02 & 0.97 & 6 & -0.13 & 0.76 & 8 & 0.25 & 0.49 & 10 \\
\hline P. vulgaris & -0.13 & 0.60 & 19 & 0.03 & 0.94 & 12 & 0.20 & 0.36 & 24 \\
\hline T. pratense & -0.02 & 0.93 & 34 & 0.05 & 0.83 & 20 & -0.01 & 0.96 & 42 \\
\hline T. repens & 0.16 & 0.38 & 34 & -0.15 & 0.52 & 20 & -0.03 & 0.85 & 41 \\
\hline
\end{tabular}

$P=0.074 ; r=-0.24, P=0.12)$. Likewise, $\mathrm{N} \%$ of bees did not increase with $\mathrm{N} \%$ of any of the four plant species or the average $\mathrm{N} \%$ of plants per plot (Table V). In all three species, nitrogen contents varied independently of $\mathrm{N} \%$ in plants, demonstrating a great potential to regulate body nitrogen content. Consequently, the homeostasis coefficient suggests complete homeostasis (Figure 2; $H_{A \text {. mellifera }}=34.2, H_{B \text {. hortorum }}=\infty$, $H_{B \text {. lapidarius }}=\infty$; the infinite $H$ in bumblebees resulted from a negative non-significant slope between plant and bee $\% \mathrm{~N}$ ).

\section{DISCUSSION}

\subsection{Resource specialisation}

In our study, diet breadth of honeybees and bumblebees was unrelated to regional abundance, possibly because they overall have wide diet breadths (Heinrich 1979; Thomson 2006), visiting $9.47 \pm 4.6$ plant species in our sample. At the regional scale of this study, our results support Goulson et al. (2008) who at a similar scale found that diet breadth is unrelated to the number of sites a bumblebee species occupies. Moreover, we found that the degree of floral specialisation (exclusiveness) was unrelated to the local and regional abundance of a species.

However, our study was conducted in a cultural landscape, which is quite heterogeneous at a small spatial scale. This means bees were often able to find many different habitat types in a 500-m radius around each grassland site (e.g. semi-natural habitat, urban habitats, forests and arable land; for details, see Kämper et al. (2016)). Indeed, in a study on the same grassland sites, it was shown that $B$. terrestris colonies in spring collected most pollen from
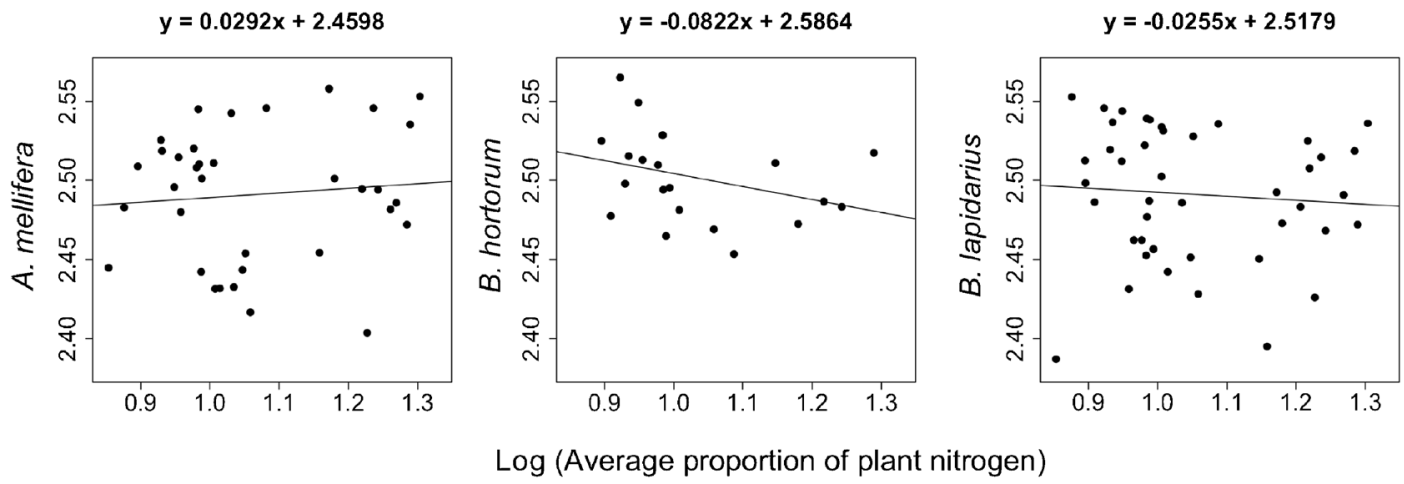

Figure 2. Average nitrogen content across four plant species (Rhinanthus alectorolophus, Prunella vulgaris, Trifolium pratense, T. repens) in relation to nitrogen content in Apis mellifera, Bombus hortorum and B. lapidarius per plot. All values are log-transformed. Regression lines and equation are given in the graph. 
woody plants instead of using the plants provided by the grassland site that surrounded each colony (Kämper et al. 2016). We conclude that our study region is not representative for regions dominated by more homogenous large arable fields with impoverished fauna and flora. Thus, we suggest while honeybees and most bumblebee species can likely find suitable floral resources in our study area, more impoverished landscapes likely represent a stronger environmental filter for bees.

In our study three bee species $(23 \%)$ responded negatively to an aggregate measure of land-use intensity, i.e. occurred at lower abundances on plots that experienced high land-use intensity (LUI), while no species responded positively. Furthermore, five bee species responded negatively to mowing intensity, four to fertilisation and one to grazing intensity. This is in accordance Weiner et al. (2014) who found that $20 \%$ of bumblebee species analysed tended to respond negatively to land use. In our study, we furthermore found that specialisation of a bee species did not predict its land-use response. In more detail, the common resource generalist $B$. lapidarius $\left(d^{\prime}=0.20\right)$, the slightly more specialised forager $B$. terrestris/lucorum species complex $\left(d^{\prime}=0.24\right)$ and the specialist forager B. wurflenii $\left(d^{\prime}=0.36\right)$ declined most with land use. This contrasts with the findings by Weiner et al. (2014) who found that specialisation predicted declines along a landuse gradient across 791 pollinator species.

Moreover, we found that $36 \%$ of plant species visited by honeybees and bumblebees in our study area responded negatively to high LUI. In particular, we found especially those plant species responding significantly negative to land use, which are frequently visited by honeybees and bumblebees. The susceptibility of insectpollinated plants to surrounding land use has been recently shown (Clough et al. 2014). Moreover, several studies have shown that the decline of preferred host plants is the key driver behind bee declines (Biesmeijer et al. 2006; Kleijn and Raemakers 2008; Scheper et al. 2014; Weiner et al. 2014).

Bombus wurflenii was the second most specialised bumblebee species in our study, probably due to the relatively exclusive use of
P. grandiflora. Prunella grandiflora is mostly restricted to calcareous grasslands, which themselves are sensitive to land use and in decline. Bombus wurflenii is short-tongued, emerges rather late in season with small to average sized nests ( $<150$ individuals) and is associated with forest edges and sometimes mountainous areas (Westrich 1990; von Hagen and Aichhorn 2003). In accordance to our finding, Goulson et al. (2005) found that emerging late in the season is correlated with rarity in bumblebees, because bumblebees often do not find favourable conditions associated with woodlands anymore and forage on unimproved grasslands instead.

\subsection{Nitrogen content and homeostasis}

Apis mellifera, B. hortorum and $B$. lapidarius exhibited nitrogen contents comparable to carnivorous insects, particularly predatory hymenopterans, for which Fagan et al. (2002) reported $11.03 \% \mathrm{~N}$ by mass on average whereas herbivores exhibit $9.65 \%$ ( $15 \%$ less). Usually, nitrogen is a scarce resource, but the nutrition of honeybees and bumblebees is based on pollen, which is relatively rich in proteins and amino acids (Vitousek and Howarth 1991; Sterner and Elser 2002; Weiner et al. 2010).

We found that nitrogen content of inflorescences/corollae increased with land use. However, our results show that the nitrogen contents in bees did not increase with landuse intensity or the nitrogen contents of four commonly visited plant species on the same plot. While we found no effects of increased nitrogen availability to individual bees, we cannot exclude that there are colony-level effects such as increased worker production. After all, experimental colonies placed at the same plots showed that total amount of protein stored as pollen by a colony correlated positively with colony growth (see Kämper et al. (2016)). An alternative explanation for the lack of such effects are the large home ranges of bees that often exceed the size of the grasslands with a certain management practice, e.g. pollen loads often contain shrubs that are not part of the grassland plot (Kämper et al. 2016). From our data, we cannot infer how much of a bee's diet 
came from the plot in which it was caught. Nevertheless, we found surprisingly stable nitrogen contents in honeybees and bumblebees, which were more constant than the nitrogen content of flowers. This shows the capability of bees to regulate their body nitrogen content almost perfectly.

Sustaining nutritional stability is a requirement to function in a changing environment, and species that can regulate nutrients should benefit from this ability (Sterner and Elser 2002). One potential mechanism to achieve homeostasis is by excreting excess nitrogen or enhancing the nitrogen assimilation of poor-quality diets (Slansky and Feeny 1977; Kagata and Ohgushi 2006). Moreover, foraging behaviour and food selection can be adjusted to up- and down-regulate nutrient levels to match specific demands (Mayntz et al. 2005). Polylectic honeybees and bumblebees may thus maintain homeostasis by seeking out plant species that match their current, or their colonies, nutrient requirements. A prerequisite is that bees are able to assess protein content of pollen prior to ingestion or provisioning. In bumblebees, studies suggested this ability and showed that workers visited patches of high-quality flowers more often and more flowers within a high-quality patch than a low-quality patch (Robertson et al. 1999). Moreover, Kitaoka and Nieh (2009) found that bumblebee pollen storage behaviour as well as foraging levels (number of workers exiting the nest) are controlled by protein quality of pollen inside the colony.

The main conclusions from this study are that three bumblebee species responded negatively to land use, while no species responded positively. Resource use did not predict species' responses to land use as a generalist forager ( $B$. lapidarius), a slightly more specialised forager (B. terrestris/ lucorum species complex) and a specialist forager (B. wurflenii) declined with land use. Moreover, our results suggest that nitrogen homeostasis against variable nitrogen contents of floral resources is common in social bees, which may be important for long-term persistence in a changing and often heavily fertilised agro-environment.

\section{ACKNOWLEDGMENTS}

We thank Melanie Chisté for her assistance with the AWM calculations and null model calculations, and Ursula Lebong and Andrea Hilpert for their help with the elemental analyses. Furthermore, we thank the managers of the three Exploratories, Kirsten Reichel-Jung, Swen Renner, Katrin Hartwich, Sonja Gockel, Kerstin Wiesner, and Martin Gorke for their work in maintaining the plot and project infrastructure; Christiane Fischer and Simone Pfeiffer for giving support through the central office; Michael Owonibi for managing the central data base; and Markus Fischer, Eduard Linsenmair, Dominik Hessenmöller, Jens Nieschulze, Daniel Prati, Ingo Schöning, François Buscot, Ernst-Detlef Schulze, Wolfgang W. Weisser and the late Elisabeth Kalko for their role in setting up the Biodiversity Exploratories project. The work has been (partly) funded by the DFG Priority Program 1374 "Infrastructure-Biodiversity-Exploratories". Field work permits were issued by the responsible state environmental offices of Baden-Württemberg, Thüringen and Bran-


work was supported by a grant from the German Research Foundation (DFG projects: EL 249/7-1).

Authors' contributions WK, TE and NB designed the study and developed the methodology. WK, CW and SK collected data. WK prepared $\mathrm{N}$ samples, CS performed the $\mathrm{N}$ analysis. WK wrote the manuscript and $\mathrm{NB}$ and TE contributed to writing.

Evaluation des effets de la spécialisation de la ressource florale et de la régulation de l'azote sur la vulnérabilité des abeilles sociales dans les paysages agricoles

Spécialisation des ressources / pollinisateur / réponse à l'utilisation des terres / homéostasie / biodiversité

Auswirkungen von Blütenspezialisierung und Stickstoffregulation auf die Anfälligkeit sozialer Bienen in Agrarlandschaften

Blütenspezialisierung / Bestäuber / Reaktion auf Landnutzung / Homöostase / Biodiversität 


\section{REFERENCES}

Atasay, A., Akgül, H., Uçgun, K., Șan, B. (2013) Nitrogen fertilization affected the pollen production and quality in apple cultivars "Jerseymac" and "Golden Delicious". Acta Agriculturae Scandinavica, Section A-Animal Science 63 (5): 460-465.

Biesmeijer, J.C., Roberts, S.P., Reemer, M., Ohlemuller, R., Edwards, M., et al. (2006) Parallel declines in pollinators and insectpollinated plants in Britain and the Netherlands. Science 313 (5785): 351-354.

Blüthgen, N., Menzel, F., Blüthgen, N. (2006) Measuring specialization in species interaction networks. BMC Ecol. 6(9).

Blüthgen, N., Dormann, C.F., Prati, D., Klaus, V.H., Kleinebecker, T., et al. (2012) A quantitative index of land-use intensity in grasslands: integrating mowing, grazing and fertilization. Basic Appl Ecol 13 (3): 207220.

Cameron, S.A., Lozier, J.D., Strange, J.P., Koch, J.B., Cordes, N., et al. (2011) Patterns of widespread decline in North American bumble bees. Proc. Natl Acad. Sci. 108 (2): 662-667.

Carvell, C. (2002) Habitat use and conservation of bumblebees (Bombus spp.) under different grassland management regimes. Biol. Conserv. 103 (1): 33-49.

Chisté, M.N., Mody, K., Gossner, M.M., Simons, N.K., Köhler, G., et al. (2016) Losers, winners and opportunists: how grassland land-use intensity affects orthopteran communities. Ecosphere. doi:10.1002/ ecs2.1545

Clough, Y., Ekroos, J., Baldi, A., Batary, P., Bommarco, R., et al. (2014) Density of insect-pollinated grassland plants decreases with increasing surrounding land-use intensity. Ecol. Lett. 17 (9): 1168-1177.

Di Pasquale, G., Salignon, M., Le Conte, Y., Belzunces, L.P., Decourtye, A., et al. (2013) Influence of pollen nutrition on honey bee health: do pollen quality and diversity matter? PLoS ONE 8 (8): e72016.

Fagan, W.F., Siemann, E., Mitter, C., Denno, R.F., Huberty, A.F., et al. (2002) Nitrogen in insects: implications for trophic complexity and species diversification. Am. Nat. 160 (6): 784-802.

Fischer, M., Bossdorf, O., Gockel, S., Hänsel, F., Hemp, A., et al. (2010) Implementing large-scale and long-term functional biodiversity research: The Biodiversity Exploratories. Basic Appl. Ecol. 11 (6): 473-485.

Gallai, N., Salles, J.-M., Settele, J., Vaissière, B.E. (2009) Economic valuation of the vulnerability of world agriculture confronted with pollinator decline. Ecol. Econ. 68(3): 810-821.

Goulson, D. (2003) Bumblebees: their behaviour and ecology. Oxford University Press, Oxford.

Goulson, D., Darvill, B. (2004) Niche overlap and diet breadth in bumblebees; are rare species more specialized in their choice of flowers? Apidologie 35 (1): 5563.
Goulson, D., Sparrow, K. (2009) Evidence for competition between honeybees and bumblebees; effects on bumblebee worker size. J. Insect Conserv. 13 (2): 177-181.

Goulson, D., Hanley, M.E., Darvill, B., Ellis, J., Knight, M.E. (2005) Causes of rarity in bumblebees. Biol Conserv. 122 (1): $1-8$.

Goulson, D., Lye, G.C., Darvill, B. (2008) Diet breadth, coexistence and rarity in bumblebees. Biodivers. Conserv. 17 (13): 3269-3288.

Goulson, D., Nicholls, E., Botias, C., Rotheray, E.L. (2015) Bee declines driven by combined stress from parasites, pesticides, and lack of flowers. Science 347 (6229): 1255957.

Heinrich, B. (1976) Resource partitioning among some eusocial insects: bumblebees. Ecology 57 (5): 874-889.

Heinrich, B. (1979) Bumblebee economics. Harvard University Press, Cambridge.

Ishii, H.S., Kadoya, T., Kikuchi, R., Suda, S.-I., Washitani, I. (2008) Habitat and flower resource partitioning by an exotic and three native bumble bees in central Hokkaido, Japan. Biol. Conserv. 141 (10): 2597-2607.

Jost, L. (2006) Entropy and diversity. Oikos 113 (2): 363-375.

Kagata, H., Ohgushi, T. (2006) Nitrogen homeostasis in a willow leaf beetle, Plagiodera versicolora, is independent of host plant quality. Entomol. Exp. Appl. 118 (2): 105-110.

Kämper, W., Werner, P.K., Hilpert, A., Westphal, C., Blüthgen, N., et al. (2016) How landscape, pollen intake and pollen quality affect colony growth in Bombus terrestris . Landsc. Ecol. 1-14

Kitaoka, T., Nieh, J. (2009) Bumble bee pollen foraging regulation: role of pollen quality, storage levels, and odor. Behav. Ecol. Sociobiol. 63 (4): 501-510.

Kleijn, D., Raemakers, I. (2008) A retrospective analysis of pollen host plant use by stable and declining bumble bee species. Ecology 89 (7): 1811-1823.

Kühsel, S., Blüthgen, N. (2015) High diversity stabilizes the thermal resilience of pollinator communities in intensively managed grasslands. Nat. Commun. 6

Leonhardt, S.D., Dworschak, K., Eltz, T., Blüthgen, N. (2007) Foraging loads of stingless bees and utilisation of stored nectar for pollen harvesting. Apidologie 38 (2): 125-135.

Mayntz, D., Raubenheimer, D., Salomon, M., Toft, S., Simpson, S.J. (2005) Nutrient-specific foraging in invertebrate predators. Science 307(5706): 111-113.

Regali, A., Rasmont, P. (1995) New bioassays to evaluate diet in orphan colonies of Bombus terrestris. Apidologie 26 (4): 273-281.

Robertson, A.W., Mountjoy, C., Faulkner, B.E., Roberts, M.V., Macnair, M.R. (1999) Bumble bee selection of Mimulus guttatus flowers: the effects of pollen quality and reward depletion. Ecology 80 (8): 2594-2606.

Roulston, T.H., Cane, J.H., Buchmann, S.L. (2000) What governs protein content of pollen: pollinator preferences, pollen-pistil interactions, or phylogeny? Ecol Monogr. 70 (4): 617-643. 
Scheper, J., Reemer, M., van Kats, R., Ozinga, W.A., van der Linden, G.T., et al. (2014) Museum specimens reveal loss of pollen host plants as key factor driving wild bee decline in the Netherlands. Proc. Natl Acad. Sci. 111 (49): 17552-17557.

Slansky, Jr. F., Feeny, P. (1977) Stabilization of the rate of nitrogen accumulation by larvae of the cabbage butterfly on wild and cultivated food plants. Ecol Monogr. 47 (2): 209-228.

Sterner, R.W., Elser, J.J. (2002) Ecological stoichiometry: the biology of elements from molecules to the biosphere. Princeton University Press, Princeton.

Tasei, J.-N., Aupinel, P. (2008) Nutritive value of 15 single pollens and pollen mixes tested on larvae produced by bumblebee workers (Bombus terrestris, Hymenoptera: Apidae). Apidologie 39 (4): 397-409.

Thomson, D.M. (2006) Detecting the effects of introduced species: a case study of competition between Apis and Bombus. Oikos 114 (3): 407-418.

Vitousek, P.M., Howarth, R.W. (1991) Nitrogen limitation on land and in the sea: how can it occur? Biogeochemistry 13 (2): 87-115. von Hagen, E., Aichhorn, A. (2003) Hummeln bestimmen, ansiedeln, vermehren, schützen. Fauna Verlag, Nottuln.

Weiner, C.N., Hilpert, A., Werner, M., Linsenmair, K.E., Blüthgen, N. (2010) Pollen amino acids and flower specialisation in solitary bees. Apidologie 41 (4): 476487.

Weiner, C.N., Werner, M., Linsenmair, K.E., Blüthgen, N. (2011) Land use intensity in grasslands: changes in biodiversity, species composition and specialisation in flower visitor networks. Basic Appl. Ecol. 12 (4): 292-299.

Weiner, C.N., Werner, M., Linsenmair, K.E., Blüthgen, N. (2014) Land-use impacts on plant-pollinator networks: interaction strength and specialization predict pollinator declines. Ecology 95 (2): 466474.

Westrich, P. (1990) Die Wildbienen Baden-Württembergs. E. Ulmer, Stuttgart.

Williams, P.H., Osborne, J.L. (2009) Bumblebee vulnerability and conservation world-wide. Apidologie 40 (3): 367-387. 